\title{
Sulfadiazine induced Stevens Johnson syndrome in toxoplasmosis patient: a case report
}

\author{
Sagar Raju*, Shilpa Shashidharan, Rani M. Kurian, Rima Ramla, Arun Paingamkulangara
}

Department of Pharmacy Practice, Mandya Institute of Medical Science, Mandya, Karnataka, India

\author{
Received: 06 August 2020 \\ Revised: 06 September 2020 \\ Accepted: 08 September 2020 \\ *Correspondence: \\ Dr. Sagar Raju, \\ Email: Sagarrrr97@gmail.com
}

Copyright: () the author(s), publisher and licensee Medip Academy. This is an open-access article distributed under the terms of the Creative Commons Attribution Non-Commercial License, which permits unrestricted non-commercial use, distribution, and reproduction in any medium, provided the original work is properly cited.

\begin{abstract}
Stevens johnson syndrome is an acute, self-limited disease, presenting as severe mucosal erosions with widespread erythematous, cutaneous macules or atypical targets. Even though sulfadiazine has been mainly associated with haematological-related adverse effects, sulfadiazine induced skin necrosis has received less attention or went unrecognized. Here is a 29-year- old Indian male received T. Sulfadiazine 500mg 1-1-1-1 and experienced a severe skin reaction which was diagnosed as stevens johnson syndrome (SJS). The above drug will be implicated in cases of stevens johnson syndrome (SJS)/toxic epidermal necrosis (TEN). There are few case reports of that have been associated with stevens johnson syndrome (SJS)/toxic epidermal necrosis (TEN). We hope that this case report creates awareness to the health care professionals. Clinicians must be aware of these adverse reactions and advise their patients to contact them as soon as they observe any unexpected clinical response. Early diagnosis helps the clinician to elude secondary infection and subsequent complications. The offending drug should be discontinued and never be rechallenged.
\end{abstract}

Keywords: Adverse drug reactions, Sulfadiazine, Stevens- johnson syndrome, Toxic epidermal necrosis

\section{INTRODUCTION}

Adverse drug reactions (ADR) are the major cause of morbidity and mortality. It accounts $6 \%$ of the total hospital admission and it leads to the economic burden to patient and health care system. ${ }^{1}$ Among the various ADR cutaneous drug reactions mainly Stevens Johnson syndrome (SJS) is a rare immune-mediated adverse reaction it is the result of extensive death of keratinocytes, which leads to the separation of areas of skin in the dermal-epidermal junction. The incidence rate of SJS is 0.05 to 2 persons per million populations per year. ${ }^{2}$ The most common drugs which cause SJS are sulphonamides, non-steroidal anti-inflammatory drugs, imidazole antifungal, cephalosporins, anticonvulsants, allopurinol, broad-spectrum bactericidal agents and highly active antiretroviral therapy highly active antiretroviral therapy (HAART) regimen. ${ }^{3}$ Sulfadiazine is the antibiotic it is mainly used in combination with pyrimethamine to treat the toxoplasmosis it inhibits the tetrahydrofolic acid formation from para- amino benzoic acid, preventing the formation of folic acid in bacterial cell. It mainly acts on the gram-positive bacteria. ${ }^{4}$

\section{CASE REPORT}

A 29-year-old male patient reported to a dermatology department at Mandya Institute of medical science on $3 / 3 / 2020$ with chief complaints of extensive rashes on the skin of the face and neck, erythema of conjunctiva, ulceration of eyelid and oral cavity and difficulty in routine oral habits since 3 days. It was also associated with pain which was sudden in onset, burning type, 
continuous, localized, and severe in intensity, aggravated on touching, speaking, eating food \& there was no relieving factor.

Patient past medical history reveals he was diagnosed to have retroviral disease (RVD) in 2011 and started on antiretroviral therapy (ART) from Mandya due to GI intolerance patient stopped ART on his own and last follow up and from 12/2/2020 he develops a complaints of deviation of angle of mouth to right, headache associated with weakness of left lower limb for which he was taken to tertiary care hospital Bangalore and found to have CNS toxoplasmosis and referred to neuro tertiary care hospital, Bangalore. From neuro tertiary care hospital, he was started to treatment on T. Sulfadiazine from 17/02/2020. Patient had taken the drug for about 9-10 days after that he develops multiple rashes all over the body.

The patient was well-oriented and on examination, multiple erythematous lesions all over the body (Figure 1) and maculopapular rash over trunk and face with vesicles and sheets of epidermal pealing over the face. No complaints of associated vomiting, fever, loose stools, and abdominal pain. Patient had no history of blurring vision, and bleeding manifestation.

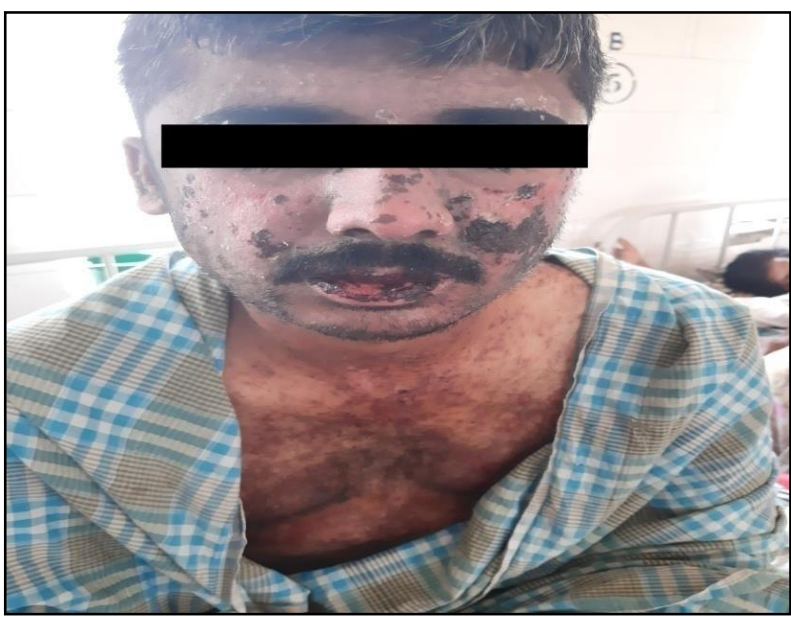

Figure 1: Maculopapular rash over the face, forehead and neck.

On intra-oral examination extensive ulcerations of the lip and the tongue were seen (Figure 2). Haemorrhagic crusted erosions were also seen on both the upper and lower lips. The oral ulcerations were developed one day prior to development of the skin lesions.

Opthalmic examination showed erythematous rashes, vesicular lesions found on both eyes of lids and conjunctiva. Cornea is clean and pupils are pharmacologically dialated. Ear, nose, and throat (ENT) examination showed maculopapular crusted lesions over nose and bilateral ear pinna.

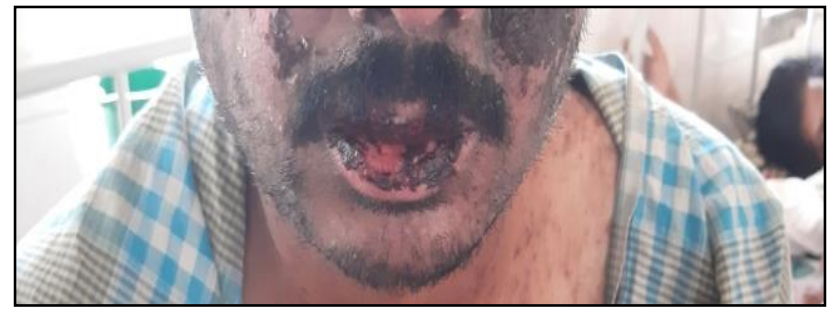

Figure 2: Ulcerations and bloody crusting lesions on surfaces of lips.

We had subjected the patient to only the hematologic investigation as the lesion being acute; the patient was under severe discomfort. His complete blood picture revealed that hemoglobin-10.5 g/dl, total leucocyte- 4900 cells/mm3, neutophill count- $79 \%$ and platelet count- 1.6 lack cells $/ \mathrm{cmm}$. Based on the subjective and objective evidence the patient was diagnosed to have a sulfa drug induced stevens johnson syndrome.

According to the expert dermatological opinion we stopped the T. sulfadiazine and started systemic steroid therapy Inj. dexamethasone $8 \mathrm{mg}$ three times a day (tid) for 10days after that bid for 3days, clonate lotion for trunk and extremities, anabel gel $0.2 \%$ for mouth ulcers, chlorhexidine mouth wash for oral, clindamycin $600 \mathrm{mg}$ iv tid is given alternative to sulfadiazine for the treatment of CNS toxoplasmosis and mannitol $20 \% 100 \mathrm{ml}$ iv bd is given for 10 days. All the lesions were start healing.

\section{DISCUSSION}

Stevens johnson syndrome is the remarkable, serious life threatening cutaneous illness. ${ }^{5}$ The International classification uses affected body surface area for the diagnosis of SJS/TEN, epidermal detachment of $>30 \%$ of body surface area defines toxic epidermal necrolysis, stevens johnson syndrome represents $<10 \%$ of body surface area and also $10-30 \%$ of body surface area represents stevens johnson syndrome/toxic epidermal necrosis (SJS/TEN) overlap. ${ }^{6}$ Stevens johnson syndrome can occur in any age group but more frequently in the women and HIV-Infected patients. The major etiology for the cause of SJS/TEN is medications and other etiologies are Hepatitis virus, Herpes virus, Mycoplasma pneumonia and other malignencies. ${ }^{7}$ The drugs which most commonly cause the SJS/TEN are allopurinol, some antibiotics, including sulfonamides, anticonvulsants such as carbamazepine, and some non-steroid antiinflammatory drugs (NSAIDs). ${ }^{8}$ SJS/TEN are usually diagnosed by clinical structures and histopathological examination. 5,6 Treating symptomatically is the only way to enhance the patient safety there is no particular guidelines for the treatment of SJS physicians and dermatologist treat the affected patients on availability of their knowledge and from their own experience. ${ }^{9}$

The study carried out by Patel et al revealed that there is very little published information regarding Sulfadiazine - 
induced toxic epidermal necrolysis. There are few cases reports with other sulphonamides in which they have been associated with toxic epidermal necrolysis. This case report creates awareness that sulfadiazine induced toxic epidermal necrolysis is possible. ${ }^{10}$

As per our observation it is drug induced SJS. Patient had taken T. sulfadiazine 500mg 1-1-1-1. This patient did not appear to have any reason for developing toxic epidermal necrolysis other than sulphur reaction. He had not received any recent immunizations. He did not have a viral infection, graft-versus-host disease, hematologic malignancy, systemic lupus erythematosus, known cerebral tumor and upper respiratory infection.

\section{CONCLUSION}

In our study we have identified that patient had developed SJS after taking T. sulfadiazine 500mg 1-1-1-1. Clinicians must be aware of these adverse reactions and advise their patients to contact them as soon as they observe any unexpected clinical response. Early diagnosis helps the clinician to elude secondary infection and subsequent complications. The offending drug should be discontinued and never be re-challenged.

\section{ACKNOWLEDGEMENTS}

We would like to give great thanks for the source of history, the patient himself and greatly appreciate the assistance and support given by the Health Care Staff of Mandya Institute of Medical Sciences, Mandya.

Funding: No funding sources Conflict of interest: None declared

Ethical approval: Not required

\section{REFERENCES}

1. Miya R, Malpani AK, Keri S, Panagaon R. Drug Induced Steven- Johnson Syndrome (SJS). Ind J Pharma Practi. 2019;12(2):133-5.
2. Aschalew S, Legesse S, Hailu L. Drug Induced Steven- Johnson Syndrome (SJS). Int Resear J Publ Heal. 2020;40(4):1-4.

3. Miya R, Malpani AK, Keri S, Panagaon R. Drug Induced Steven-Johnson Syndrome (SJS). Ind J Pharm Pract. 2019;12(2):133.

4. Ben-Harari RR, Goodwin E, Casoy J. Adverse Event Profile of Pyrimethamine-Based Therapy in Toxoplasmosis: A Systematic Review. Dru R D. 2017;17(4):523-44.

5. Agarwal S, Balaji O, Navin Patil. Aceclofenacinduced stevens- Johnson syndrome after one single dose. Asian j Pharma Clin Res. 2018;11(9):1-2.

6. Bhanu LP, Swamy KM, Nasiruddin M, Naveen HD, Venkataraman R. Stevens-Johnson syndrome induced by phenytoin: a case report. Int $\mathrm{J}$ Bas Cinic Pharmaco. 2017;6(1):208.

7. Fakoya AO, Omenyi P, Anthony P, Anthony F, Etti $\mathrm{P}$, Otohinoyi DA, et al. Stevens-Johnson syndrome and toxic epidermal necrolysis; extensive review of reports of drug-induced etiologies, and possible therapeutic modalities. Macedon J Medic Scien. 2018;6(4):730.

8. Wong A, Malvestiti AA, Hafner MD. StevensJohnson syndrome and toxic epidermal necrolysis: a review. Revis da Associa Médica Brasil. 2016;62(5):468-73.

9. Megha Patel, Amit Raval. Phenytoin induced Toxic Epidermal Necrolysis: A Case Study. J Pharma Resea. 2010;3(9):1-3.

10. Patel TK, Barvaliya MJ, Sharma D, Tripathi C. A systematic review of the drug-induced StevensJohnson syndrome and toxic epidermal necrolysis in Indian population. Ind $\mathbf{J}$ Dermato Venereo Lepro 2013;79(3):389.

Cite this article as: Sagar R, Shilpa S, Rani MK, Ramla R, Arun P. Sulfadiazine induced- stevens johnson syndrome in toxoplasmosis patient: a case report. Int J Basic Clin Pharmacol 2020;9:1615-7. 